NBER WORKING PAPER SERIES

\author{
PRIVATIZING SOCIAL SECURITY: \\ FIRST ROUND EFFECTS OF A \\ GENERIC, VOLUNTARY, PRIVATIZED \\ U.S. SOCIAL SECURITY SYSTEM
}

\author{
Alan L. Gustman \\ Thomas L. Steinmeier
}

Working Paper 5362

\author{
NATIONAL BUREAU OF ECONOMIC RESEARCH \\ 1050 Massachusetts Avenue \\ Cambridge, MA 02138 \\ November 1995
}

We would like to acknowledge support for both of us from the National Institute on Aging, and support for Gustman from a Rockefeller Center Reiss Family Fellowship at Dartmouth College. We also would like to thank Richard Disney and Olivia Mitchell for helpful comments. This paper is part of NBER's research programs in Aging and Labor Studies. Any opinions expressed are those of the authors and not those of the National Bureau of Economic Research.

() 1995 by Alan L. Gustman and Thomas L. Steinmeier. All rights reserved. Short sections of text, not to exceed two paragraphs, may be quoted without explicit permission provided that full credit, including $\odot$ notice, is given to the source. 


\title{
PRIVATIZING SOCIAL SECURITY: \\ FIRST ROUND EFFECTS OF A \\ GENERIC, VOLUNTARY, PRIVATIZED \\ U.S. SOCIAL SECURITY SYSTEM
}

\begin{abstract}
This paper investigates individual responses to a simple scheme to privatize social security. The analysis explores the sensitivity of outcomes to how individuals project life expectancy, how they value spouse and survivor benefits, and to expected future reductions in social security benefits. Depending on assumptions made, first year participation ranges from $20 \%$ to almost $100 \%$. Estimated time paths for taxes decline immediately with privatization, but the decline in benefits grows slowly over a period of two or three decades. Labor force participation rates are not greatly affected by privatization, even if major changes in pensions are induced.
\end{abstract}

\author{
Alan L. Gustman \\ Department of Economics \\ Dartmouth College \\ Hanover, NH 03755 \\ and NBER
}

\author{
Thomas L. Steinmeier \\ Department of Economics \\ Texas Tech University \\ Lubbock, TX 79409
}




\section{Introduction.}

Pressures are increasing to reduce social security benefits further and to raise social security taxes. ${ }^{1}$ Among other things, these pressures are created by adverse financial projections for social security, reflecting demographic and other trends, and the perception that savings in the U.S. is too low. Some are proposing more sweeping changes, including means testing social security benefits. ${ }^{2}$ Others are proposing to privatize the social security system, or some portion of it. ${ }^{3}$ Similar pressures have spawned partially privatized systems in Britain, Latin America, Australia and elsewhere.

This paper investigates some first order effects of adopting a simple scheme to privatize social security in the United States. Under this scheme, for each year an individual opts out of social security, the individual and the employer pay no payroll taxes; but $1 / 35$ th of future benefits are lost to the individual. The taxes that would have been paid are instead invested in a

${ }^{1}$ The financial outlook for the social security system is less favorable than was projected at the time of the 1983 reforms. See, for example, the 1995 Annual Report of the Board of Trustees of the OASDI Trust Fund. Benefits might be reduced by speeding up the changes called for under the 1983 reforms (see Gustman and Steinmeier, 1991 for an analysis of labor supply effects of an accelerated program), by further increasing the retirement age, by reducing cost of living adjustments, or by making other changes. It is also possible to raise income taxes on social security benefits by counting a larger fraction of the benefits in income. For evaluations of these and other suggestions, see the recently released report from The Technical Panel on Trends and Issues in Retirement Savings of the 1994-95 Advisory Council on Social Security.

${ }^{2}$ Means testing of social security benefits has been discussed by The Bipartisan Commission on Entitlements and Tax Reform, among others.

${ }^{3}$ Senators Kerrey and Simpson have introduced legislation based on the options discussed by the Bipartisan Commission on Entitlements and Tax Reform to privatize a portion of social security using two percent of the payroll tax. The Technical Panel on Trends and Issues in Retirement Savings of the 1994-95 Advisory Council on Social Security also discussed the possibility of partial privatization through converting part of the Social Security Trust Funds into individual accounts. 
mandatory individual retirement account (IRA) on behalf of the worker. The scheme is generic in that it has no special design features or requirements, such as requirements for additional savings. There is no required basic benefit. Moreover, there is total rather than partial privatization in that the full payroll tax paid by the employee and employer is invested in the IRA. $^{4}$

The analysis includes first round responses by individuals, but does not include a complete redesign of the system on the revenue side to insure balance. ${ }^{5}$ Because only those who experience a financial advantage will choose to opt out, and the analysis does not include redesigning the revenue system, the privatized system analyzed here will clearly not be revenue neutral. Rather, it would require a subsidy from general revenue, which is not modeled. There are no revenue constraints imposed, no new taxes to insure that the budget is balanced, either under the current system or under the proposed system. Accordingly, this scheme and the effects examined here cannot be the final word. Rather, the analysis involves a look at the first order effects of such a program.

We ask about the consequences of introducing a privatized alternative for social security for program participation, labor supply, benefits and payroll taxes. Thus we are asking about the behavioral response of potential participants to a privatization alternative before any further changes are imposed to bring about fiscal balance, improved savings, or to meet other constraints.

${ }^{4}$ The British system is partially voluntary. See, for example, Disney and Whitehouse (1992) and Brugiavini, Disney and Whitehouse (1993).

${ }^{5}$ For discussions which do take adjustments on the revenue side into account, see Feldstein (1995) and Kotlikoff (1995). 
The paper begins by exploring the incentive structure to opt out of social security that is created by this privatization proposal. It analyzes the way in which incentives to participate or opt out of social security depend on earnings, spouse and survivor benefits, on the length of time the individual plans to work, and for those with a history of participation under the current system, on the past history of covered employment.

Retirement and social security participation are projected on the basis of past behavior, applying a structural model to simulate outcomes under the rules that apply to these cohorts under present law, and then under the assumption that in 1996 a privatized system is established. Data for the simulation analysis are from the Survey of Consumer Finances. ${ }^{6}$ The simulation analysis focuses on cohorts who would first become eligible to opt out during the transition period to a privatized system. ${ }^{7}$ The cohorts have already generated a coverage history under the current social security system, and must choose whether to opt out for a portion of their remaining work life.

The scheme analyzed here is likely to overstate participation in and the costs of a

${ }^{6}$ Data from the 1989 Survey of Consumer Finances is examined to determine, for males born from 1934 through 1959, which ones would benefit from choosing a privatization option and which ones would benefit by remaining under social security.

${ }^{7}$ At this stage the analysis is confined to males, but it may be extended to families. We have confined the present analysis to males for a number of reasons. With regard to the benefit structure, as discussed below, there are complex issues that must be faced in designing how benefits are to be determined for couples under such a privatization option. At this early stage of analysis, we thought it best to focus on the incentives affecting the choices made by individual earners, eliminating the need to adopt what will be debatable rules that may take a number of forms. In addition, the work history in the SCF leaves a great deal to be desired, and the work history is of particular importance in determining the relation among spouse benefits under social security. Moreover, although we have an estimate of a joint utility function for husbands and wives (Gustman and Steinmeier, 1994), a much simpler preference function available to us has been estimated for males. 
voluntary, privatized system. ${ }^{8}$ Indeed, the present analysis produces estimates of the population that would find such a scheme attractive under the most favorable type of arrangement that we can visualize. In particular, we know that those who would choose to opt out of the present system include all individuals who are expecting to pay more in payroll taxes than they would receive in benefits. Given the redistributive nature of the benefit formula, and the windfall that accrued to earlier generations of social security participants, the number that would choose to participate in a privatized system is going to be very large. However, our expectation is that any scheme to privatize social security that was adopted would involve a less favorable tradeoff than our generic scheme, requiring, as the generic system does not, a basic payroll tax contribution to cover the redistributive portion of social security, and perhaps also to cover the costs of deficits expected in the future. Moreover, voluntary privatization schemes may carry other requirements, e.g., requirements for additional savings (Feldstein and Samwick, 1995). In addition, at this stage the analysis does not explicitly value disability insurance. Although the labor supply effects and participation patterns simulated for the program analyzed here will overstate participation in and costs of whatever privatization scheme is likely to be proposed, the analysis of incentives, and the simulation of labor supply and related effects, do provide insight into the changes that any privatization scheme may induce. They are a starting point for the analysis of the effects of privatizing social security in the United States.

The analysis of incentives under the privatization scheme appears in Section II. Section III discusses the simulation methodology and Section IV presents a simulation analysis. It begins

${ }^{8}$ Of course, the scheme may be made mandatory, so that there will be full participation. Many privatization schemes for social security have mandatory participation. See Diamond's (1993) description of the Chilean system, for example. 
with a model of retirement and a projection of the opportunities for earnings and pension incomes into retirement, all computed for the sample of males from the SCF born from 1934 through 1959. Utility function parameters used in the simulation are based on the labor supply response observed for cohorts who have already retired. ${ }^{9}$ Outcomes are simulated in Section IV. Section $\mathrm{V}$ concludes the paper.

\section{Incentives For Participation In A Privatized System}

\section{A. Basic Features Of The Privatization Scheme.}

The privatization scheme which is explored here is a very basic scheme. Let us begin by describing the basis for calculating social security benefits for those that participate in some years but not others. If the individual opts out for one or more years, we assume that the primary insurance amount (PIA) is reduced proportionately. That is, if the individual opts out for 20 years, the PIA would be only $43 \%$ ( 15 years out of the 35 years that is currently used in the PIA calculations) of the PIA he would receive if he had not opted out.

Next, consider how the years opted out affect the average indexed monthly earnings (AIME) calculations. It is probably infeasible to include all years, whether in or out of the system, in these calculations. Otherwise, individuals could concentrate earnings in years they opt out of the system, which would reduce taxes without affecting AIME amounts. However, it would be unfair simply to exclude years that the individual opts out from the calculations, while still using the high 35 our of 40 years of earnings. This approach would impose a double penalty

\footnotetext{
${ }^{9}$ The preference functions have been estimated from data for males in the Retirement History Survey in Gustman and Steinmeier (1994).
} 
for the years out: first, the AIME would be proportionately reduced because the years out of the system, since zeros would effectively replace years with earnings, and secondly, the PIA would be proportionately reduced.

A plausible way around this problem would be to exclude, from both the numerator and denominator of the AIME calculations, years in which the individual opts out. For instance, if the individual opts out for 20 years, the AIME would be the average of the highest 15 of the remaining years of indexed earnings, rather than the highest 35 as would otherwise be the case.

\section{B. Benefits For Those Who Are Covered By The Privatization Option For Their Entire Worklife.}

To simplify the discussion of benefits under this privatization scheme, we make the assumption that the annual earnings $w_{t}$ increase proportionately to the average wage index. This implies that the indexed wage used in the AIME calculations is a constant $\mathrm{w}^{10}$ We also assume that the discount rate is equal to the growth rate of the average wage index. This means that the discounted value of the social security taxes is constant at $B w$, where $B$ is the tax rate if the individual remains in the system.

Let $\mathrm{x}$ be the total number of years of work and $\mathrm{x}_{\mathrm{s}}$ be the number of years that the individual remains in the social security system. $x_{0}=x-x_{s}$ is the number of years the individual opts out of the system. The modified AIME discussed above is given in equation 1 .

${ }^{10}$ This assumption is only approximate. The actual rules state that wages before age 60 are indexed up to age 60 for the AIME formula, and that wages after age 60 enter the formula unindexed. 
(1)

$$
\text { ALME }=\frac{x_{s} w}{35-x_{0}}=\frac{x_{s} w}{35-\left(x-x_{0}\right)} \quad \text { if } x<35
$$

$$
=\quad w \quad \text { if } x \geq 35
$$

The PIA is a quasi-concave function of the AIME where the function $\mathrm{f}$ is $90 \%$ of the first $\$ 426$ of AIME, $32 \%$ of AIME between $\$ 426$ and $\$ 2567$, and $15 \%$ of AIME over $\$ 2567 .{ }^{11}$ The PIA is given in equation 2.

$$
\begin{array}{rlrl}
P L A & =\left(1-\frac{x_{0}}{35}\right) f(A I M E) & & \text { if } x_{0}<35 \\
& =0 & \text { if } x_{0} \geq 35
\end{array}
$$

The first factor on the right hand side of equation 2 simply reflects that the PIA is reduced proportionately for years out of the system.

The value of the stream of social security benefits, less the value of the contributions, is given by

$$
V=g\left(a_{0}+x\right) P L A-x_{s} \beta w
$$

where $g\left(a_{0}+x\right)$ is the annuitized value the social security benefits for each $\$ 1$ of PIA. The individual starts work at age $a_{o}$ and retires at age $a_{o}+x$. For example, if the individual retired at age 63 , the value of a $\$ 1$ annuity (including the cost of living increases) would be $\$ 13.93$, and the individual would be eligible for $86.7 \%$ of the PIA (because he retired two years before the

${ }^{11}$ These are the 1995 bend points. 
normal retirement age). The value of the function $g$ would be $\$ 13.93$ times $86.7 \%$, or $\$ 12.07 . .^{12}$

\section{Optimal Number Of Years In The System Holding Length of Worklife Fixed.}

In this section we illustrate the type of calculation the individual makes by showing that for this simple case where wage growth matches the interest rate, an individual planning to work more than 35 years will find it optimal either to be entirely in, or entirely out of the social security system for his working life, depending on length of worklife and earnings. It is not optimal for such an individual to stay in for only some years and be out for the remaining years. An individual working less than 35 years may, however, find an interior solution optimal and may spend only a fraction of his working life in the system.

Let us first investigate the optimal number of years to remain in the system, given that the individual plans to work $x \geq 35$ years, and wage growth matches the interest rate. Substituting the AIME and PIA formulas into the value formula yields:

$$
\begin{aligned}
V & =g\left(a_{0}+x\right)\left(1-\frac{x-x_{s}}{35}\right) f(w)-x_{s} \beta w & \text { if } x-x_{s}<35 \\
& = & \text { if } x-x_{s} \geq 35
\end{aligned}
$$

Differentiating this expression by $\mathrm{x}_{\mathrm{s}}$, holding $\mathrm{x}$ constant, yields

${ }^{12}$ In this analysis, and in the subsequent empirical analysis, we ignore the effects of known differences among individuals in life expectancy that may make social security more attractive to individuals with a long life expectancy, and less attractive to those with a short life expectancy. 


$$
\begin{aligned}
\frac{\partial V}{\partial x_{s}} & =\frac{1}{35} g\left(a_{0}+x\right) f(w)-\beta w & \text { if } x-x_{s}<35 \\
& =\quad-\beta w & \text { if } x-x_{s} \geq 35
\end{aligned}
$$

Consider now how this scheme to privatize social security affects the incentive to work. Under the proposed scheme, an individual is assumed to be free to opt out of social security by making a contribution of 12.4 percent (the OASDI tax rate) of salary into an approved IRA, rather than paying the payroll tax. Thus the individual decides whether this year's social security is a good deal, in which case he pays the full tax and stays in the system, or he decides that it is a bad deal, in which case he saves the $12.4 \%$ in the IRA and opts out of the system for that year. ${ }^{13}$ The marginal return for years in the system is clearly negative if $x_{s}$ is less than $x-35$ (which implies $x-x_{s} \geq 35$ ). The marginal return if $x_{s}$ is greater than $x-35$ depends on the sign of $(1 / 35) g\left(a_{o}+x\right) f(w)-B w$, which is independent of $x_{o}$ but whose sign is ambiguous. If it is negative, then the individual's marginal return for years in the system is negative for all years, and he should clearly opt out of the system completely. If, however, it is positive, the individual receives a negative return for the first $\mathrm{x}-35$ years he opts out, and a positive return for the remaining 35 years. In this case, he will either want to opt out for all years or stay in for all years, depending on which strategy gives the higher value. If he opts out for all years, the value is zero, while if he stays in, the value will be given by

$$
V=g\left(a_{0}+x\right) f(w)-x \beta w
$$

${ }^{13}$ We assume that the IRA would be made available in installments starting at age 62 , so that the decision is not driven by liquidity constraint considerations. 
Thus, the individual will stay in for all years if the above value is positive.

If the individual plans to work for less than 35 years, the value function is:

$$
V=g\left(a_{0}+x\right)\left(1-\frac{x-x_{s}}{35}\right) f\left(\frac{x_{s} w}{35-\left(x-x_{s}\right)}\right)-x_{s} \beta w
$$

Differentiating this with respect to $x_{s}$ yields:

(8)

$$
\begin{aligned}
\frac{\partial V}{\partial x_{s}} & =g(.)\left\{\frac{1}{35} f(.)+\left(1-\frac{x-x_{s}}{35}\right) f^{\prime}(.) \frac{w\left[35-\left(x-x_{s}\right)\right]-x_{s} w}{\left[35-\left(x-x_{s}\right)\right]^{2}}\right\}-\beta w \\
& =g(.)\left\{\frac{1}{35} f(.)+\frac{1}{35} f^{\prime}(.) \frac{\left(35-x_{0}\right)}{35-\left(x-x_{s}\right)}\right\}-\beta w \\
& =\frac{1}{35} g(.)\left\{f(.)+f^{\prime}(.) \frac{(35-x) w}{35-\left(x-x_{s}\right)}\right\}-\beta w
\end{aligned}
$$

Differentiating again by $x_{s}$ yields, after some manipulation:

$$
\frac{\partial^{2} V}{\partial x_{s}^{2}}=\frac{1}{35} g(n) \frac{(35-x)^{2} w^{2}}{\left[35-\left(x-x_{s}\right)\right]^{3}} f^{\prime \prime}(.)
$$

Since $\mathrm{f}$ is quasi-concave, $\mathrm{f} "$ is non-positive, and so is $\partial^{2} \mathrm{~V} / \partial \mathrm{x}_{\mathrm{s}}^{2}$. This implies that any interior solution for $\mathrm{x}_{\mathrm{s}}$ on the interval $(0, \mathrm{x})$ must occur where the first partial derivative of $\mathrm{V}$ is zero. If $\partial \mathrm{V} / \partial \mathrm{x}_{\mathrm{s}}$ is uniformly negative in the interval, then the optimal solution is to opt out of the system entirely. If $\partial \mathrm{V} / \partial \mathrm{x}_{\mathrm{s}}$ is uniformly positive, the individual should stay in the system throughout his working years. 
To summarize, in this simple case of wage change equal to the interest rate, an individual planning to work more than 35 years should be either in or out of the social security system for his working life, depending on whether equation (6) is positive or negative. It is not optimal for such an individual to stay in for only some years and be out for the remaining years. An individual working less than 35 years may, however, find an interior solution optimal and may spend only a fraction of his working life in the system.

\section{Variation In Optimal Number of Years In The System As Length of Worklife Varies.}

The next question is to investigate how the optimal number of years in the system varies with the length of the working life. As previously suggested, the answer to this question depends on whether the individual plans to spend at least 35 years in the work force.

For an individual who plans to spend more than 35 years working, the solution is relatively simple. Recall that the individual will stay in if equation (6) is positive.

Differentiating this equation with respect to $\mathrm{x}$, which is the length of the work life, yields:

$$
\frac{\partial V}{\partial x}=g^{\prime}(.) f(w)-\beta w
$$

This expression is unambiguously negative, since $\mathrm{g}^{\prime}$ is nonpositive. ${ }^{14}$ If the individual finds it advantageous to opt completely out of social security when $x=35$, he will find it advantageous to do so for any value of $\mathrm{x}$ greater than 35 as well. If the individual remains in social security when $x=35$, the value of social security in equation (6) declines as $x$ increases until, at some

${ }^{14} \mathrm{~g}($.$) is the change in the benefits from (i) collecting benefits for fewer years, if the$ individual is over 62 , and (ii) the effects of the early retirement penalty or the delayed retirement credit. If the individual can increase benefits simply by delaying registering, he is assumed to do so. Hence, $\mathrm{g}($.$) cannot increase; otherwise the individual can realize the gain by delaying$ registering, without working more years. This implies $\mathrm{g}^{\prime}() \leq$.0 . 
point $\mathrm{x}^{*}$ the individual opts out. In others words, if $\mathrm{x}<\mathrm{x}^{*}$, the individual remains in, but if $\mathrm{x}>$ $\mathbf{x}^{*}$, the individual opts out.

For $\mathrm{x}<35$, we may find out how increasing the work life affects $\mathrm{x}_{\mathrm{s}}$ simply by differentiating equation (8):

$$
\frac{\partial V}{\partial x_{3} \partial x}=\frac{1}{35}\left\{g^{\prime}(.)\left[f(.)+f^{\prime}(.) \frac{(35-x) w}{35-\left(x-x_{s}\right)}\right]+g(.) f^{\prime \prime}(.) \frac{[(35-x) w]^{2}}{\left[35-\left(x-x_{s}\right)\right]^{3}}\right\}
$$

Since $\mathrm{g}^{\prime}$ and $\mathrm{f}^{\prime \prime}$ are non-positive, this derivative is non-positive as well. Recall that the derivative in equation (8) falls with increasing $x_{s}$, and that the optimal $x_{s}$ is where the derivative is equal to zero.

Figure 1 depicts the situation. Equation (11) shows that the curve $\partial \mathrm{V} / \partial \mathrm{x}_{\mathrm{s}}$ shifts downward as $\mathrm{x}$ increases, which implies that the point where the curve crosses zero moves leftward. In other words, as the number of years worked increases, the optimal length of time to remain in the social security system decreases.

A final task is to show that as $\mathrm{x}$ approaches $35, \mathrm{x}_{\mathrm{s}}$ must approach either 35 or zero. Suppose, to the contrary, that

$$
\lim _{x \rightarrow 35} x_{s}=a
$$

where $\mathrm{a}$ is between 0 and 35 . Then it follows that from equation (1)

$$
\lim _{x \rightarrow 35} A I M E=w
$$

and the limiting value of equation (3) is 


$$
\lim _{x \rightarrow 35} V=g\left(a_{0}+35\right) f(w)-35 \beta w
$$

If the right hand side of equation (14) is positive, then the individual will find it optimal to stay in social security the full 35 years. If the right hand side is negative, the individual will find it optimal not to stay in social security at all. Thus, the assumption that if as $\mathrm{x}$ approaches $35, \mathbf{x}_{\mathrm{s}}$ can approach an intermediate value leads to a contradiction (except if the right hand side of equation (14) is exactly zero).

Figure 2 displays two alternative relationships between the number of years of work and the number of years in social security which are consistent with the above results. One possibility (depicted by the circles) is for the individual to stay in social security as long as the years of work do not exceed some critical number $\mathbf{x}^{*}$, and to opt out of social security completely if years of work exceed $x^{*}$. The number of years in social security follows the $45^{\circ}$ line up to $\mathrm{x}^{*}$, and then falls discontinuously to zero. Another possibility (depicted by the squares) is for the worker to stay in social security if the years of work is sufficiently small, and to opt out an increasing amount of time if years of work is larger. In this case the number of years in social security follows the $45^{\circ}$ line up to $x^{* *}$, and then falls gradually toward zero. Note that according to the results of the previous paragraph, it must arrive at zero before the years of work increases to 35 .

The first path is more likely to occur if the wage level is low, and the second path is more likely if the wage level is higher. This can be seen by evaluating the right hand side of equation (6) at $\mathrm{x}=35$. Since $f$ is concave, the expression is more likely to be negative the higher the value of $w$. If it is negative, then the optimal value of $x_{s}$ at $x=35$ is zero, and the optimal 
path will be like the second path. If the expression is positive when evaluated at $x=35$, then the optimal value of $x_{s}$ is 35 , and the optimal path is like the first path.

Some numerical examples will illustrate the above model. Assume the individual begins work at age 25 and plans to work for a given number of years, and that the interest rate is equal to the wage growth rate, and both are two percent above the inflation rate. The decision is how many years to remain in social security. Table 1 contains results for individuals with three alternative wage rates $(\$ 15,000, \$ 30,000$, and $\$ 45,000)$ and several alternative work horizons. The entries in the table are the net value of remaining in social security for the given work horizon and a given number of years in social security. (For reasons of space, Table 1 shows the values for 5 -year increments of years in social security). For instance, $\$ 5054$, which is the second figure in the next to the last column, indicates the net reward for a person with a wage of $\$ 15,000$ who works for 35 years and who spends 30 of those years in the social security system. This individual would retire at age 60 and would normally be eligible to receive $80 \%$ of his Primary Insurance Amount at age $62 .{ }^{15}$ However, since he opted out of the system for 5 years, he receives only $85.7 \%(30 / 35)$ of the benefits he would otherwise be entitled to. The present value of the benefits he receives are $\$ 60,854$. On the tax side, this individual pays additional taxes of $\$ 55,800$ ( $12.4 \%$ times 30 years times $\$ 15,000$ ). The value of benefits net of taxes is $\$ 8324$, as indicated in the table.

The table shows that for an individual earning $\$ 15,000$ per year, the value of remaining in social security is positive for most work horizons and most of the potential choices for the

${ }^{15}$ The individual in this table is assumed to turn 62 in the year 2000 , which means that the normal retirement age is still 65 and the delayed retirement credit is $6.5 \%$ per year. 
number of years to remain in the system. The right three columns are probably most relevant, since they correspond to the individual (who begins work at age 25) retiring at age 55 to 65 . In each column, the individual will want to choose the number of years to remain in the system so as to maximize the value. If the work horizon is less than 40 years, the optimal choice turns out to be to remain in the system during the individual's entire working life. In the final column, associated with a work horizon of 40 years, the negative figures reflect a net cost if the individual were to remain in the system. This net cost can be avoided by opting out of the system.

Not surprisingly, social security is less attractive to individuals with higher income levels. At $\$ 30,000$ of annual earnings, the values are all negative if the individual plans to work 35 or 40 years. Such an individual would want to opt out of social security entirely. If the individual plans to work 20 years or less, social security has a net positive value for whatever length of time the individual remains in the system. However, this value is maximized if the individual remains in the system only for a short time, about five years in most cases. The same pattern prevails at $\$ 45,000$ of annual earnings, except that the magnitudes of the losses are considerably larger. Note that the loss of individuals with $30-40$ year work horizons will result in substantial costs to the system. A $\$ 45,000$ a year individual with a 35 year work horizon currently contributes almost $\$ 60,000$ to the system, and the system will lose this amount if he is able to opt out.

Table 2 summarizes the optimal years in social security and the value of spending those years for each section of Table 1. For instance, with an income of $\$ 30,000$ and a work horizon of 10 years, it is optimal to spend about 5 years in social security. These figures appear in the second pair of columns of Table 2 . Note that the patterns of years in social security conform to the patterns derived in Figure 2. For a wage of $\$ 15,000$, the optimal path is path 1 , which 
follows the 45 degree line if the work horizon is 37 years or less and drops to zero if the work life horizon is 38 years or more. For a wage of $\$ 30,000$, the optimal path is path 2 . Along this path, the individual follows the 45 degree line up to a work horizon of 6 years, then gradually reduces his years in social security with increasing work horizons until he drops out of the social security system entirely for work horizons of 35 years or longer. If the wage is $\$ 45,000$, it is the same result except that the individual follows the 45 degree line up to a work horizon of only 4 years. ${ }^{16}$ C. Analysis for Workers Already in the System.

Continuing our simple example and basic analysis of the decision to opt out of social security for a generic privatization system, we consider workers who have already been in the system for several years at the time the privatized system is introduced. We continue to maintain the simple assumption that wage growth equals the interest rate. Let $x_{i}$ denote the number of years that the individual has already accumulated in the system. As before, the analysis is somewhat different depending on whether the total work horizon is greater or less than 35 years.

For individuals with a work horizon less than 35 years, equation (7) is still valid as the value formula. Two possibilities arise in this situation: either the $x_{s}^{*}$ which maximizes $V$ is less than $x_{i}$ or it is greater. If $x_{s}^{*}>x_{i}$, the individual wishes to remain in the system for a longer period of time than he has already accumulated in it, and he can achieve the unconstrained maximum. If $x_{s}^{*}<x_{i}$, recall from equation (9) that the value function is a concave function of $x_{s}$. The concavity implies that if the unconstrained $x_{s}^{*}<x_{i}$, the optimal constrained $x_{s}$

${ }^{16}$ Tables 1 and 2 assume mortality rates from the 1990 Vital Statistics. If mortality is expected to be gradually reduced over time, the present value of any level of social security benefits will be higher. This will imply that fewer individuals would opt out of social security, and for a shorter period of time. 
(constrained to be at least $x_{i}$ ) will be on the constraint. That is, if the individual would have stayed in the system fewer than $x_{i}$ years if he were making the choice at the beginning, he will drop out of the system immediately if he is allowed to after $\mathbf{x}_{\mathbf{i}}$ years.

If the individual has a work horizon of longer than 35 years, the analysis of the last section, which showed that the individual will still either stay with the social security system for the full period or will drop out immediately, is still valid. The choice depends on a comparison of the net values for the two alternatives. If he stays in for the full period, equation (6) gives the net value. If he opts out immediately, the value is

$$
\begin{aligned}
V & =g\left(a_{0}+x\right)\left(1-\frac{x-x_{i}}{35}\right) f(w)-x_{i} \beta w & & \text { if } x<x_{i}+35 \\
& = & & \text { if } x \geq x_{i}+35
\end{aligned}
$$

depending on whether the remaining horizon is less than or greater than 35 years. The net value of staying the full period vs. dropping out immediately is the difference between equations (6) and (15), which is

$$
\begin{aligned}
\Delta V & =\frac{x-x_{i}}{35}\left\{g\left(a_{0}+x\right) f(w)-35 \beta w\right\} & & \text { if } x<x_{i}+35 \\
& =g\left(a_{0}+x\right)-\left(x-x_{i}\right) \beta w & & \text { if } x \geq x_{i}+35
\end{aligned}
$$

The individual will drop out for the remaining years when $\Delta \mathrm{V}$ is less than zero. Comparing this result with the similar condition in equation (6), it is evident that, for a given value of $x, V$ in 
equation (6) is more likely to be negative than is $\Delta \mathrm{V}$ in equation (16). ${ }^{17}$ In other words, if the individual has accumulated some years under social security and intends to work more than 35 years, he is more likely to stay in social security than if he were making the choice with no prior history.

\section{Extensions of the Model.}

The preceding analysis has been of a relatively simple model for social security privatization. There are a number of directions in which the model may be extended to make it more realistic, although at some increase in analytical complexity. Several of these extensions are discussed in this section, though without formal derivations.

The model assumes that the interest rate is the same as the wage growth rate, so that the discounted wage is the same in all periods. Two factors may be introduced to cause a divergence between these two rates. First, the interest rate may exceed the growth rate of wages in the economy. In this case, individuals who participate in social security for only a few years would want to opt out early in their careers, since the discounted value of the taxes would be highest in those years. A second factor is that individual wages may not grow at the same rate as wages overall. This would make it more advantageous to opt out in high wage years, when taxes are high. If wages are a concave function of experience, those high wage years would occur at midcareer. ${ }^{18}$ These factors may make partial participation in social security desirable even for

${ }^{17}$ If $x<x_{i}+35$, the term $g\left(a_{o}+x\right) f(w)-x \beta w$ in equation (6) is less than $g\left(a_{o}+x\right) f(w)-$ $35 \beta w$ in equation (16), since $x>35$ in this case.

${ }^{18}$ For the model where wages follow a random walk process, see Samwick (1993). For analysis of the participation decision in the British system when earnings vary from year to year, see Brugiavini, Disney and Whitehouse (1993). 
those who work more than 35 years.

Another extension is to consider the utility value of the benefits. Social security may be more valuable than a simple calculation of expected monetary value might indicate. This occurs because the markets for private annuities are affected by the adverse selection problem. Part of the value of social security is that it provides some protection against a long lifespan, and this protection is difficult to replace in the private annuity market. The protection is even more important because it holds its value in real terms due to the indexing of social security benefits to the comsumer price index, and this kind of protection in real terms is impossible to find in the private market.

A third extension concerns the returns on the privatized IRA's. In the analysis above, the discount rate that is used to evaluate the desirability of social security should conceptually be the return that individuals could earn if they were investing the funds themselves. If choices are available for the IRA investments, one might wish to allow for the possibility that different individuals might earn different returns by investing in different kinds of assets, which involve different risks.

Other extensions involve requirements that may be imposed by a privatized system. For example, to encourage savings, it might be required that an individual who opts out of social security save more than the payroll tax in a special IRA. If defined contribution pensions count for this purpose but defined benefit pensions do not (perhaps because of the difficulty of whether to value the pension accruals as legal or projected benefits), there may be substantial pressure to change the form of pensions from defined benefit to defined contribution. The workers most affected are the higher earnings groups who are likely to be in a position to control pension 
decisions. Hence, it seems likely that unless something like the British system is adopted, which credits pensions under defined benefit plans, large-scale conversions might well take place, with attendant reductions of pension incentives and the likely increase in the retirement age. ${ }^{19}$

A final extension would be to consider how this plan would work in the context of a household. For a single-earner household, the decision is whether to make the availability of spouse and widow benefits dependent on whether the primary earner stays in the system. If the spouse and widow benefits do not depend on whether the primary earner stays in, the possibility arises that benefits may be paid to families who have opted out of the system for most if not all of the time. If the benefits do depend on whether the primary earner stays in, then the possibility arises that the earner may look at his own welfare, opt out of the system, spend the retirement benefits during his own lifetime, and leave the widow in poverty, much as what happened before pension benefits were required to be joint. This scenario might be avoided if the payout of the retirement account were limited to an amount based on the joint survivor probabilities, or if the spouse were required to conspicuously assent to an action that would forego her survivor benefits, as under the Retirement Equity Act.

The decision is more complicated if both individuals work. The question is whether to make spouse and survivor benefits conditional on whether the worker stays in, or whether the spouse stays in. Suppose that spouse and survivor benefits are paid only if the spouse stays in, and consider a family with a high earning worker and a low earning spouse. The high earning

${ }^{19}$ However, to the extent that pensions are serving useful functions, such as effectively terminating implicit labor contracts, there might be an offset to the social security advantages gained by converting defined benefit pensions to plans that would satisfy social security requirements. 
worker may well opt out of social security, but the spouse will probably stay in, since her minimal tax payments are buying a substantial amount of spouse and survivor benefits. In the limit, this case is like the case of a single earner and may result in substantial benefits being paid to families whose primary earner has opted out of the system. Suppose instead that spouse and survivor benefits are payable to the degree that the worker stays in. In this case, at least one partner will drop out of the system. If the higher earner stays in, then the taxes paid by the lower earner are buying almost no additional benefits, and that earner will surely drop out. If the higher earner drops out, the lower earner will benefit from the progressivity of the PIA formula, and may well stay in. In either case, the social security system will lose the taxes from one individual, with probably only a minimal reduction in benefit obligations.

\section{The Simulation Methodology.}

In order to investigate the likely effects of privatization in a more concrete setting, we conduct simulations for a transition cohort of individuals who are midstream in their careers when the privatization is made available. The scheme which is to be simulated is the generic program described above, to be made available beginning in 1996. There are many outcomes of potential interest, but we shall focus on the fraction of the workforce participating in a privatized social security system, labor force participation patterns, and benefit payouts and payroll tax payments under the remaining federal system.

Labor supply is assumed to be determined in the context of a life cycle model with a perfectly operating capital market. The opportunity set for the simulations comes from 30 to 55 year old males in the 1989 Survey of Consumer Finances. These cohorts of males would have 
already spent several years under the current system if privatization were introduced in 1996, but they would still have a considerable period of time under the privatized system. The life cycle preferences come from a model we have previously estimated. We simulate the choices that individuals with these preferences would make, given the opportunity set both with and without privatization, and compare the outcomes.

\section{A. The Opportunity Set.}

The opportunity set for the simulation model is estimated for males in the 1989 Survey of Consumer Finances who were working full-time and who were neither self-employed nor employed by government. ${ }^{20}$ Wages in full-time jobs and in partial retirement are calculated, with wages being assumed to a quadratic function of experience. ${ }^{21}$ Pension accruals are reported for covered individuals by their employers and are used to calculate the pension accrual rates associated with alternative retirement dates. ${ }^{22}$ The current social security law is coded and applied to each individual in the sample, including rules governing the earnings test, the delayed retirement credit, and benefit recomputation, as they separately apply to each individual according to year of birth. The interest rate and overall wage growth rate correspond to the longterm intermediate social security projections. ${ }^{23}$ Where applicable, the IRA in a privatized system

\footnotetext{
${ }^{20}$ These simulations focus on the transition cohorts of these groups. Since social security contains workers from the excluded groups, there is no obvious reconciliation if one were to try to derive implications for the finances of the entire social security system.

${ }^{21}$ The coefficients of experience and experience squared are 0.0138 and -0.000283 , and the coefficient of experience interacted with education is 0.000996 .

${ }^{22}$ Where the individuals own pension was unavailable, pensions from other individuals with the same personal and job characteristics (union status, employer size, wage level, etc.) were used.
} 
is assumed to earn this interest rate. ${ }^{24}$ The chance of falling into poor health is modeled as a hazard and is built into the opportunity set.

The simulation algorithm does not assume that the opportunity set is continuous. There is a discontinuity created by the minimum hours constraint on the main job. If the individual leaves the main job for part-time work, the wage declines, and this decline is assumed to be irreversible. In addition, the incentives to postpone retirement which are created by the pension plan are frequently discontinuous. Large returns are often gained if the covered worker waits until he meets the plan's eligibility requirement for early or normal retirement. These discontinuities are taken into account in calculating the worker's optimal date of retirement.

\section{B. Preferences.}

The preference function used in the simulations has been estimated with data from the 1969-79 Retirement History Study using the opportunity sets covering workers in that study. The lifetime utility function for the model is given by

$$
U=\sum\left[\frac{1}{\alpha} C_{t}^{\alpha}+e^{X_{t} \beta \cdot \epsilon} f\left(L_{t}, \delta\right)\right]
$$

where $C_{t}$ is consumption at time $t$ and $L_{t}$ is leisure at time $t . f\left(L_{t}, \delta\right)$ is 0 at full-time work, 1 in retirement, and an intermediate value, related to $\delta$ (with $\delta<1$ ), for partial retirement work. ${ }^{25}$

${ }^{23}$ These assumptions are $6.3 \%$ for the interest rate, $5.0 \%$ for wages, and $4.0 \%$ for prices (1995 Report of the Board of Trustees of the Social Security System, p. 12).

${ }^{24}$ Recent evidence has suggested that individuals are relatively conservative in their investment choices when investing in their IRA's or in defined contribution plans where they have a choice of investments.

${ }^{25}$ Specifically, for partial retirement work, $f\left(L_{1, \delta}\right)=\left(L_{t}^{\delta}-L_{f}^{\delta}\right) /\left(1-L_{f}^{\delta}\right)$, where $L_{f}$ is the leisure associated with full-time work. 
If $\delta$ is close to $1, f\left(L_{t}, \delta\right)$ is approximately proportional to leisure for partial retirement work, while if $\delta$ is large and negative, $f\left(L_{1}, \delta\right)$ is almost 1 . This means that the closer $\delta$ is to unity, the greater is the relative disutility of partial retirement work, and the shorter and less frequent are periods of partial retirement. $\epsilon$ determines the relative utility of leisure as opposed to consumption. In the utility function, both $\epsilon$ and $\delta$ are taken to be individual fixed effects coming from the distributions $f(\epsilon)=N\left(0, \sigma_{\epsilon}\right)$ and $f(\delta)=\gamma e^{\gamma(1-\delta)}, \gamma>0$.

The parameters of the utility function, which are $\alpha, \gamma, \sigma_{\epsilon}$, and the elements of $B$, are estimated using data from the Retirement History Survey and reported in Table 3. These results use a likelihood function developed and estimated in our previous work (Gustman and Steinmeier, 1985, 1986a and b, and 1994). Since the time period of the RHS, however there has been a sharp trend to earlier retirement by the younger cohorts. ${ }^{26}$ Only about a quarter of this trend can be accounted for by changes in pensions and social security (Anderson, Gustman and Steinmeier, 1994), and as a result the simulations with the SCF sample understate retirement, with individuals working approximately three years too long. This should not affect the differences in outcomes between runs with the current and privatized social security system, but it will affect the levels of benefits.

\section{Simulation Results}

Simulations have been conducted for private sector, not self-employed males in the 1989

${ }^{26}$ In the simulations we fix the vintage coefficient at the average value of the RHS. If we use the SCF vintages in the simulations, they very substantially overpredict retirement. This overprediction probably occurs because the coefficient of this variable, which is estimated using the 1906-1911 cohorts in the RHS, is being extrapolated far outside the estimation range to the SCF cohorts, who were born between 1934 to 1959. 
Survey of Consumer Finances (SCF) who were between the ages of 30 and 55 in 1989. The sample included 186 individuals without a pension and 692 with a pension, and 1000 simulations were run for each of these individuals. Each set of simulations is run under current law (the base case) and under a privatization program. For each set of simulations, results are calculated for the percentage participation in the social security program (or, equivalently, the percentage participation in the privatization program), the labor force participation rate, and the amounts of social security taxes and benefits. To keep track of benefits paid on behalf of, and contributions made by those who did not survive, the present value figures for benefits and taxes pertain to the original cohort population and not just to survivors.

The analysis is conducted using alternative assumptions about the life expectancies that govern the economic decisions of individuals, about how the workers in the sample value the spouse and survivor benefits offered by social security, and about whether workers anticipate the possibility of reduced benefits in the future. ${ }^{27}$ The simulations focus on transition cohorts who are old enough to have already spent several years under the current system. If the privatized system were introduced in 1996 , their ages would range from 37 to 62 . At younger ages, many individuals in this sample would not be able to opt out because they reached the specified age before 1996, while at older ages some workers will have already retired. Consequently, the results cannot be viewed as an indication of the eventual steady state but are best viewed as the likely experience of the transition cohorts.

\footnotetext{
${ }^{27}$ These alternative treatments are adopted because we do not know how males evaluate spouse and survivor benefits. They also are adopted to investigate the sensitivity of the findings to the fact that, for reasons discussed previously, the model is confined to males and consequently ignores spouse employment. For a joint model of retirement of husbands and wives, see Gustman and Steinmeier (1994).
} 


\section{A. Effects on Participation In Social Security.}

Figure 3 shows the reduction in social security participation between a regime where the privatized system is available from 1996 on for those who choose it, and the current system, where there is no privatized alternative. By social security participation, we mean both having earnings at a particular age or during a particular year, and choosing to pay taxes into the social security system rather than opting out and paying an equivalent amount into a qualifying IRA. Part A shows the reduction in social security participation by age, while Part B shows the corresponding reduction by year.

Consider first the reduction in the social security participation on the assumption that individuals value fully the potential spouse and survivor benefits, and they anticipate the same pattern of mortality as is observed in the 1990 Vital Statistics. ${ }^{28}$ These results are demarcated by diamonds and labeled "standard life table" in Figure 3. In Part A of the figure, the inverted U shape of the curve results from two factors. At younger ages, a relatively large fraction of these cohorts is older than the indicated age when privatization is introduced in 1996, and so cannot participate in a privatized system at those ages. At older ages, much of the sample is retired and cannot participate in the privatized system. Only those in the middle age groups could potentially participate in a privatized system in the sense of contributing into a qualifying IRA rather than paying social security taxes.

As seen in Part B of Figure 3, the largest number opt out of social security in the initial

\footnotetext{
${ }^{28}$ A more complete analysis would explicitly consider the work history of each spouse. Under a privatized system, participation in the labor market and in social security would depend on the rules adopted for determining benefits within the family. As suggested in Section II, this is an important and complex enough topic to be left for future work.
} 
year, 1996. As labor force participation falls, fewer people are left to opt out, and so in later years the difference in social security participation brought about by the privatization program is lower. At its peak effect, the program reduces participation by over a half among the members of these cohorts who are still alive at the time.

The next set of results, demarcated by squares and labeled "projected life table" in Figure 3 , includes a time trend in mortality and, in addition, differential mortality rates according to family income and initial marital status. First, the 1990 Vital Statistics mortality rates are adjusted to reflect a reduction in mortality of $1.22 \%$ per year. ${ }^{29}$ Then, for whites and non-whites separately, the mortality rates for married and unmarried individuals are adjusted by fractions so that overall mortality rates are the same as the projected rates. ${ }^{30}$ The mortality rates in various income brackets are also adjusted down for high income individuals and up for low income individuals in such a manner that the overall mortality rates are the same as the projected rates. ${ }^{31}$

Using these projected mortality figures, we see that many fewer individuals would leave the social security system for a privatized system if they factored in the effects of the extended life expectancy on their social security benefits. Specifically, in Part A of Figure 3 just over a

${ }^{29}$ This trend is based on results reported in Panis and Lillard (1995), Table 1.

${ }^{30}$ Panis and Lillard (1995) estimated the ratio of mortality rates between married and unmarried white males to be 0.781 . Applying this result to our study, we multiply the overall mortality by .987 for married white males and by 1.264 for unmarried white males.

${ }^{31}$ Duleep (1989, Table 1) found the following ratios of mortality among the various income classes: $1.59(<\$ 2 \mathrm{~K}), 1.79(\$ 2-4 \mathrm{~K}), 1.04(\$ 4-6 \mathrm{~K}), 0.90(\$ 6-8 \mathrm{~K}), 0.87(\$ 8-10 \mathrm{~K}), 0.71$ $(>\$ 10 \mathrm{~K})$. For blacks and whites separately, the widths of these intervals were adjusted so that the total mortality rate of the group was the same as the overall projected rate. For whites, this means that the Vital Statistics mortality is multiplied by 1.59 for family income levels of $\$ 0$ 11,368 , by 1.79 for family income levels of $\$ 11,368-22,736$, by 1.04 for family income levels of $\$ 22,736-34,104$, and so on. For blacks, the width of the income intervals is $\$ 6,641$. 
fifth of covered individuals would opt to participate in a privatized system in 1996. These cohorts fully value the expected spouse and survivor benefits, and these are considerably higher under the projected life tables. The annuity promised by the social security system is more valuable the longer the participant expects to live, and the change in life expectancy due to the projections is substantial.

The third set of results, demarcated by triangles in Figure 3, uses the 1990 life tables but assumes that, for married workers, the individual places zero value on the benefits that will be available to the spouse when retired or as survivor benefits that will be available to her if he should die. ${ }^{32}$ Under the joint assumption of 1990 life tables and valuation of only own benefits, in 1996 everyone in these cohorts drops out of the social security system. Clearly the effect of the introduction of a privatized system on participation in social security will be very much dependent on how spouse and survivor benefits are valued.

The forth set of results shown in Figures $2 \mathrm{~A}$ and 2B, demarcated by circles, uses the 1990 life tables and assumes that spouse and survivor benefits are valued on a par with the basic benefit. However, these simulations assume that individuals believe that all benefits will be only $80 \%$ as valuable as projected under current law. Under this scenario, four fifths of the working population will opt out of social security in $1996 .^{33}$

B. Effects Of Privatizing Social Security On Labor Supply.

${ }^{32}$ Since many spouses will be entitled to at least some benefits based on own work, the marginal values of spouse and survivor benefits are overstated in the previous calculations.

${ }^{33}$ According to data recently collected in the Health and Retirement Survey, future recipients place the odds that Social security benefits will be decreased in the future at 6 out of 10. See Gustman, Mitchell and Steinmeier (1995). 
Essentially, the changes in social security participation rates pictured in Figures 3 have two components: changes in labor supply and changes in participation conditional on labor supply. As Figure 4 suggests, the change in labor supply is so small that the change in social security participation conditional on labor supply is the dominant decision.

Figure 4 indicates the effects of privatizing on labor force participation rates. ${ }^{34}$ Part A illustrates the same four variations as were plotted in Figure 3, which allow for different assumptions regarding mortality rates and the value placed on future benefits. Examining the scale on the y-axis, it is apparent that there is only a very small effect of privatizing the social security system on labor force participation. The effects are largest when the projected mortality rates are used, but privatizing never reduces labor force participation by more than two percentage points as the small work incentives in the social security system are lost. This result is consistent with earlier findings (Gustman and Steinmeier, 1985). The social security system is approximately actuarially fair for many of those in the cohorts we analyze, and so is the privatized system. ${ }^{35}$

The generic system analyzed here does not impose any special eligibility requirements for participants in the social security system to participate in the privatized system. From the perspective of the individual, this is the most favorable of the circumstances that could be expected, and is unlikely to emerge under any privatization initiative. It certainly is likely that

${ }^{34}$ Comparable patterns are obtained when the figures for earnings changes are plotted.

${ }^{35}$ Available evidence suggests that labor force participation responds to changes in the reward for marginal effort around the age of retirement, such as the discontinuities created by bonuses or declines in benefit accrual often brought about by provisions of pension plans. But the evidence also suggests that retirement is not very responsive to changes in wealth effects from higher wages (Gustman and Steinmeier, 1986a). 
there will be some basic contribution required of any individual who would like to opt out of the system to cover both the redistributive portion of the benefit formula and the underfunding of the system. Another possibility is that participation in the privatized system will require that the individual save more than the payroll tax contribution. ${ }^{36}$

Any requirement for additional savings might encourage firms that offer defined benefit plans to change them to qualifying types of defined contribution plans, so that their employees could meet the savings requirements of a privatized system with little further reduction in consumption. ${ }^{37}$ We have conducted a set of runs on the assumption that defined benefit plans are converted to defined contribution plans, altering retirement incentives. The results of one such set of runs are shown in Part B of Figure 4. The findings suggest that labor force participation for those in their sixties might increase slightly as a result of privatization, instead of being reduced as was found in the scenarios in Part A of Figure 4.

\section{Effects on Present Values of Taxes and Benefits.}

Table 4 reports the averages under alternative scenarios of the present value of total earnings, the present value of total payroll taxes paid into the social security system by the cohort

${ }^{36}$ The effects of such a requirement would depend in part on the savings that the individual already had. Under such a system, higher income individuals would be more likely to opt out because of the regressivity of the benefit formula, because they are more likely to meet any savings requirement, and because with incomes above the social security break even, lower savings rates on total income would be required of higher income individuals. For those who would not otherwise accumulate the required level of savings to meet any eligibility requirements, the extent of participation in a privatized system would depend on the disutility of additional required savings. This is an issue that our model does not address. See Feldstein and Samwick (1995) for further discussions.

${ }^{37}$ In the British system, one may opt out of the equivalent of our social security system by participating in the equivalent of a defined benefit pension. See Disney and Whitehouse (1993) for further discussion. 
members, the present value of all benefits paid to the cohort members including own, spouse and survivor benefits, and the present value of own benefits. These values are averages per member of the simulated cohorts. For instance, the entry of $\$ 131,412$ in the column labelled "taxes" means that on average, each member of the simulation group paid that amount in social security taxes, discounted to 1989 , over his lifetime. As previously noted, to keep track of benefits paid on behalf of, and contributions made by those who did not survive, these present values pertain to the original cohort population and not just to survivors.

Changes in the present value of earnings with privatization are minuscule. Earnings decline very slightly if a privatized system were instituted and there were no changes in pensions, while if defined benefit plans were abolished, there would be a slight increase in earnings. Importantly, these cohorts will have spent two thirds of work lives under social security by the time the system changed in 1996. But even then, these changes are very small.

The fall in social security participation with privatization is mirrored in the declines in benefits and taxes paid. The benefits reported here include the full value of retired worker, spouse, and survivor benefits, even in cases where workers do not fully value these benefits themselves. Again, these figures refer to the entire lifetime of the individual, not just to the time since the system is privatized. If spouse and survivor benefits are fully valued, taxes and benefits fall by about fifteen percent. The differences are very small with the excess in the decline of taxes over benefits amounting to about two percent of the basic lifetime tax payment. The fall in both taxes and benefits are about half as large when the projected life tables are used.

When social security potential beneficiaries undervalue payments to spouse or survivor, or discount the future value of payments, then adjustments are made so that benefits actually fall 
more than taxes do, especially in the case when only own benefits are valued by the individual. To the extent that spouses have worked full-time and only own benefits are valued, the figures in the last column may be relevant. In that case, and assuming the worker takes into account only his own benefits, taxes would fall considerably more than benefits ( $\$ 48,972$ vs. $\$ 30,207)$.

\section{The Time Path Of Outcomes.}

From the perspective of policy, it is not enough to know that there are small lifetime differences in present values of benefits and contributions for these cohorts resulting from privatization. An important fraction of the taxes charged to these cohorts has already been paid and has been used to finance benefits received in past years by older generations of retirees. The time paths illustrated in Figures 5 and 6 give a strong indication of the nature of the financial problems that will be faced as a result of privatization. Under all scenarios, the decline in taxes is immediate, while the decline in benefits does not become substantial until well into the next century. This is a source of an immediate cash flow problem for the system, one that is going to be made significantly worse when older and younger generations are included in the analysis. While the differences in paths are smaller when projected life tables are used, the news is not really encouraging because benefits are so much higher under the projected life tables.

\section{Conclusion}

This paper has examined some consequences of adopting a generic policy to privatize the social security system involving a simple opt out provision with no changes in the basic benefit or tax structure, and no special savings requirements. For each year an individual opts out of social security, the individual is permitted to trade one thirty-fifth of social security benefits in 
exchange for the employer and employee payroll taxes that otherwise would have been charged. This amount must be deposited in a qualified IRA, which will be made available at retirement. We have examined the incentives created by this privatization scheme, and the likely effects of such a scheme on the labor supply, program participation and social security taxes and benefits for males who were born between 1934 and 1959.

We examine the incentives from the privatization scheme in the context of an analytical model with constant wage growth. Assuming an interest rate which equals the wage growth rate, the model indicates that an individual planning to work more than 35 years will find it optimal either to be entirely in, or entirely out of the social security system for his working life, depending on length of worklife and earnings. It is not optimal for such an individual to stay in for only some years and be out for the remaining years. An individual working less than 35 years may, however, find an interior solution optimal and may spend only a fraction of his working life in the system.

In contrast to the assumptions made in the analytical model, we know that real wage profiles are nonlinear and that wage growth declines with increasing experience, causing the relationship between wage growth and the interest rate to vary over the life cycle. Furthermore, the steepness of the wage profile in not constant among the population, but rather varies with years of schooling and other factors. As a result, the conclusion that individuals who have a work horizon of more than 35 years will either stay entirely in the system or leave it entirely is softened; in some circumstances, workers may choose to participate in the system for some years and opt out for others. In the simulation analysis reported in the paper, we do allow for a nonlinear growth of wages. 
Using estimates of an opportunity set data for a sample of males from the 1989 Survey of Consumer Finances together with parameters estimated for a structural retirement model using data from the Retirement History Study, we simulate the changes in behavior induced when introducing a privatized system. Since the sample was 30 to 55 years old when the SCF was conducted in 1989 , this simulation analysis focuses on cohorts who are in the transition phase of the switch to privatized alternatives to social security. The simulation analysis suggests the orders of magnitude involved in adjustments to a privatization scheme.

We find that continued participation in the social security system, and the course of taxes and benefits, are sensitive to a number of factors. Considerations of fundamental importance are: What is the expected life table governing individual decisions? Do the respondents value the spouse and survivor benefits provided by the social security system? Do the respondents expect promises of benefits from social security to be met, or do they expect to receive lower benefits than they have been promised?

Depending on the assumptions used, the first year participation in a privatized system could be as little as $20 \%$ or as high as almost $100 \%$. The time paths for taxes and benefits by year indicate that privatization will create a substantial cash flow problem for social security. The decline in taxes is immediate, but the decline in benefits grows slowly over a period of two or three decades. In contrast to substantial changes in social security participation, taxes and benefits, labor force participation rates are not greatly affected by the introduction of the privatized alternative. This is true even if major changes in the pension system are induced to allow more workers to qualify for the privatized scheme.

As long as privatization is voluntary, any effort to determine the effects of a social 
security privatization program, whether involving partial or full privatization, will have to address the basic behavioral questions that the simulations are so sensitive to. What life expectancy will participants use to project the value of social security? How are spouse and survivor benefits valued? To what extent do participants expect reduced benefits from social security?

The findings about changes in labor force participation suggest that simulation models of the effects of privatization may, as a first approximation, ignore labor supply responses. But before adopting this conclusion, there are two caveats. First, these simulations were based on preferences measured for a population that retired in the 1970s. With the trend to earlier retirement, retirement outcomes today may be more sensitive to social security changes, and any induced changes in pension plans, than our findings indicate. In addition, changes in social security may affect the labor supply of other family members. Further analysis along these lines should deal explicitly with the rules governing privatization in a family context, and should utilize a model in which labor market decisions within the family are jointly determined.

More generally, the behavior considered here, as a first approximation, includes program participation and labor market decisions when social security and a private alternative are governed by the current tax and benefit structure. The next step is to introduce a number of complications. These same choices should be considered under the options that will become feasible once taxes and benefits are adjusted to bring the system into financial balance. A variety of risks need to be integrated into the analysis, as well as the demands for annuities and related insurance. Further, if privatization programs are proposed, they are likely to come with additional restrictions, such as requiring additional savings. These restrictions may create 
additional behavioral responses. In the case of additional savings requirement, models which allow for capital market imperfections may improve the analysis (Feldstein and Samwick, 1995). 
Table 1

Net Value of Remaining in Social Security Using 1990 Mortality Tables

Years in Social Security

40

35

30

25

20

15

10

5

0

40

35

30

25

20

15

10

5

0

40

35

30

25

20

15

10

5

0

5

10

15

Number of Years of Work

Wage: $\$ 15,000$

$\begin{array}{rrrrr} & & & & -3437 \\ & & 8783 & 5054 & -4275 \\ 14556 & 11669 & 7940 & 4211 & -5112 \\ 13714 & 10827 & 7098 & 3369 & -6787 \\ 12871 & 9985 & 6256 & 2527 & -7625 \\ 8737 & 9143 & 5414 & 1685 & -8462 \\ 0 & 8300 & 4571 & 842 & -9300 \\ & 0 & 0 & 0 & 0\end{array}$

Wage: $\$ 30,000$

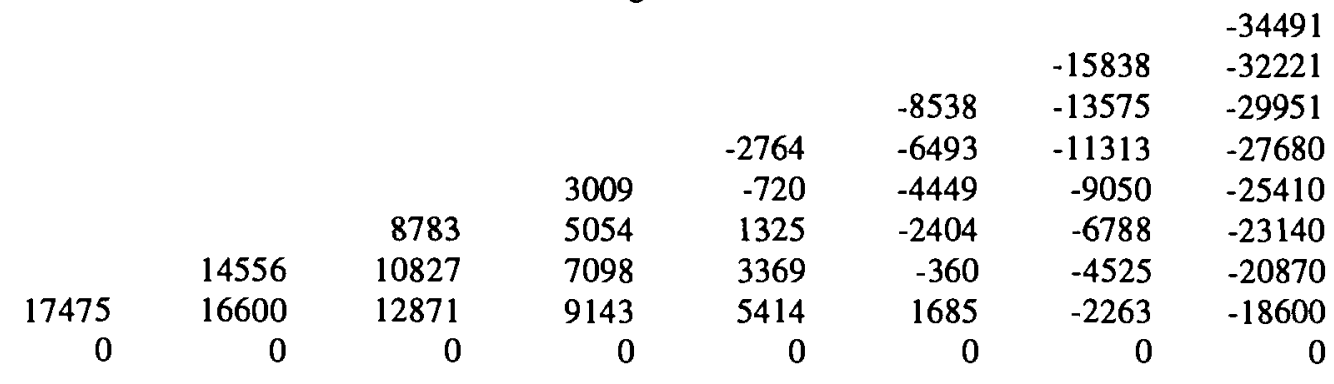

Wage: $\$ 45,000$

\begin{tabular}{|c|c|c|c|c|c|c|c|}
\hline & & & & & & & -87857 \\
\hline & & & & & & -59894 & -79292 \\
\hline & & & & & -41013 & -51338 & -70726 \\
\hline & & & & -22131 & -32457 & -42782 & -62161 \\
\hline & & & -8538 & -13575 & -23900 & -34225 & -53596 \\
\hline & & 122 & -3607 & -7336 & -15344 & -25669 & -45031 \\
\hline & 8783 & 5054 & 1325 & -2404 & -6788 & -17113 & -36465 \\
\hline 17443 & 13714 & 9985 & 6256 & 2527 & -1202 & -8556 & -27900 \\
\hline 0 & 0 & 0 & 0 & 0 & 0 & 0 & 0 \\
\hline
\end{tabular}


Table 2

Optimal Choices for Years to Remain in Social Security Using 1990 Mortality Rates

\begin{tabular}{|c|c|c|c|c|c|c|}
\hline \multirow[b]{3}{*}{$\begin{array}{c}\text { Years of } \\
\text { Work }\end{array}$} & \multicolumn{6}{|c|}{ Wages } \\
\hline & \multicolumn{2}{|c|}{$\$ 15,000$} & \multicolumn{2}{|c|}{$\$ 30,000$} & \multicolumn{2}{|c|}{$\$ 45,000$} \\
\hline & $\begin{array}{c}\text { Years in Social } \\
\text { Security }\end{array}$ & Value & $\begin{array}{c}\text { Years in Social } \\
\text { Security }\end{array}$ & Value & $\begin{array}{c}\text { Years in Social } \\
\text { Security }\end{array}$ & Value \\
\hline 1 & 1 & 1747 & 1 & 3495 & 1 & 5242 \\
\hline 5 & 5 & 8737 & 5 & 17475 & 4 & 18429 \\
\hline 10 & 10 & 17475 & 5 & 16600 & 3 & 15686 \\
\hline 15 & 15 & 17443 & 4 & 13280 & 3 & 11957 \\
\hline 20 & 20 & 14556 & 3 & 9960 & 2 & 9214 \\
\hline 25 & 25 & 11669 & 2 & 6640 & 2 & 5486 \\
\hline 30 & 30 & 8783 & 1 & 3320 & 1 & 2743 \\
\hline 35 & 35 & 5896 & 0 & 0 & 0 & 0 \\
\hline 40 & 0 & 0 & 0 & 0 & 0 & 0 \\
\hline
\end{tabular}


Table 3

Parameters of the Utility Function

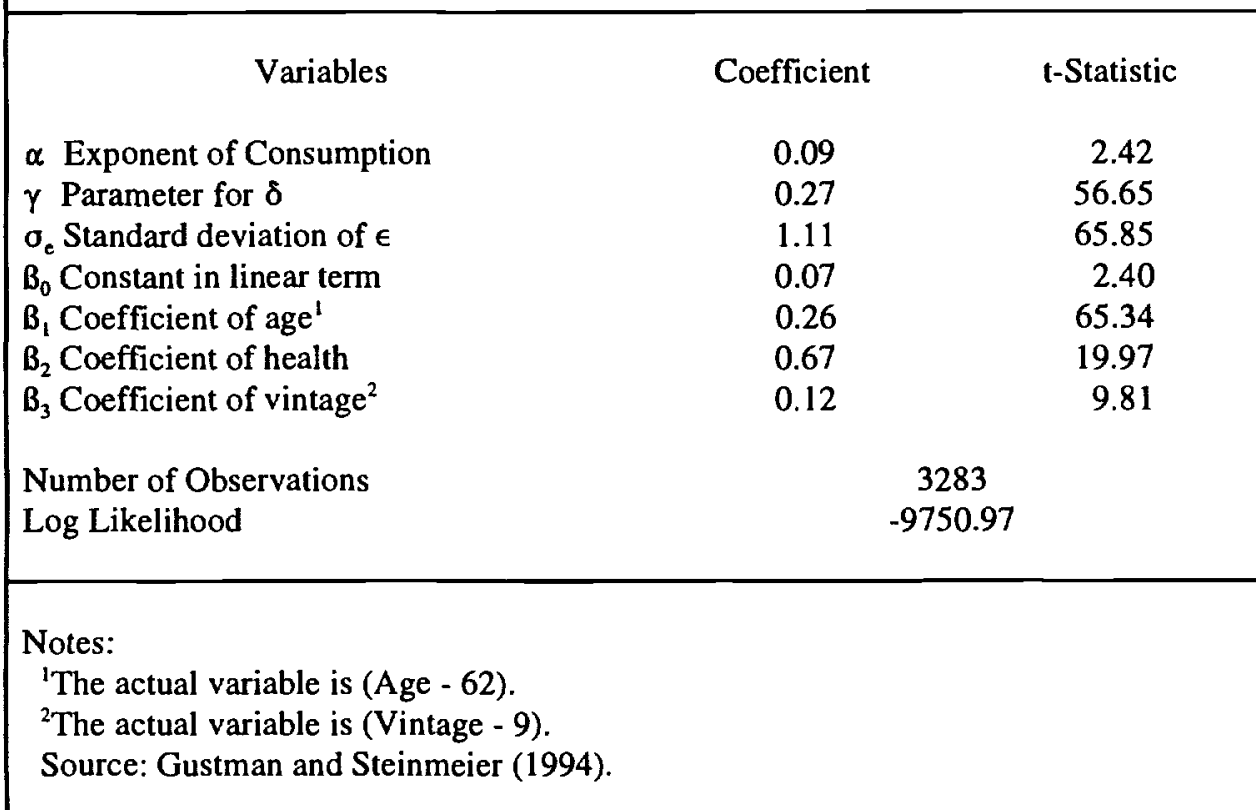


Table 4

Present Values of Earnings, Social Security Payroll Taxes, and Benefits for Cohorts Born from 1934 to 1959

(Thousands of 1989 Dollars)

\begin{tabular}{|c|c|c|c|c|}
\hline- & Earnings & Taxes & Total Benefits & Own Benefits \\
\hline \multicolumn{5}{|l|}{1990 Life Tables } \\
\hline Current System & $\$ 1,426,405$ & $\$ 131,412$ & $\$ 122,081$ & $\$ 61,608$ \\
\hline Privatized System & $1,421,047$ & 111,312 & 104,807 & 51,449 \\
\hline Privatized - Current & $(5,358)$ & $(20,100)$ & $(17,274)$ & $(10,159)$ \\
\hline \multicolumn{5}{|l|}{ Projected Life Tables } \\
\hline Current System & $1,444,322$ & 132,946 & 154,709 & 85,290 \\
\hline Privatized System & $1,435,965$ & 124,874 & 148,418 & 80,052 \\
\hline Privatized - Current & $(8,357)$ & $(8,072)$ & $(6,291)$ & $(5,238)$ \\
\hline \multicolumn{5}{|c|}{ Only Own Benefits Valued" } \\
\hline Current System & $1,426,673$ & 131,414 & 120,330 & 63,656 \\
\hline Privatized System & $1,427,436$ & 82,442 & 63,101 & 33,449 \\
\hline Privatized - Current & 763 & $(48,972)$ & $(57,229)$ & $(30,207)$ \\
\hline \multicolumn{5}{|c|}{ Benefits Discounted 20\%" } \\
\hline Current System & $1,426,999$ & 131,477 & 122,063 & 61,593 \\
\hline Privatized System & $1,423,920$ & 95,266 & 85,249 & 42,167 \\
\hline Privatized - Current & $(3,079)$ & $(36,211)$ & $(36,814)$ & $(19,426)$ \\
\hline \multicolumn{5}{|c|}{ DB Converted to DC Plans" } \\
\hline Current System & $1,426,405$ & 131,412 & 122,081 & 61,608 \\
\hline Privatized System & $1,432,599$ & 112,327 & 105,217 & 51,498 \\
\hline Privatized - Current & 6,194 & $(19,085)$ & $(16,864)$ & $(10,110)$ \\
\hline
\end{tabular}




\section{References}

Brugiavini, Agar, Richard Disney and Edward Whitehouse. 1993. "Choice of Pension Arrangements Under Uncertainty In The U.K." Royal Economic Society Conference.

Diamond, Peter. 1993. "Privatization of Social Security: Lessons From Chile." NBER Working Paper No. 4510.

Disney, Richard and Edward Whitehouse. 1992. "The Personal Pensions Stampede." Report Series, London: Institute for Fiscal Studies.

Duleep, Harriet. 1989. "Measuring Socioeconomic Mortality Differentials Over Time." .. Demography.

Feldstein, Martin. 1995. "Would Privatizing Social Security Raise Economic Welfare?" National Bureau of Economic Research, Working Paper 5281. September.

Feldstein, Martin and Andrew Samwick. 1995. "Is Voluntary Privatization of the U.S. Social Security Program Possible? Mimeo, Cambridge.

Gustman, Alan L., Olivia S. Mitchell, and Thomas L. Steinmeier. Forthcoming. "Retirement Research Using the Health and Retirement Survey." Journal of Human Resources.

Gustman, Alan. L. and Thomas L. Steinmeier. 1985. "The 1983 Social Security Reforms and Labor Supply Adjustments of Older Individuals in the Long Run." Journal of Labor Economics 3, pp. 237-253.

. 1986a. "A Structural Retirement Model." Econometrica 54(3), pp. 555584.

. 1986b. "A Disaggregated Structural Analysis of Retirement By Race, Difficulty of Work and Health." Review of Economics And Statistics, 67(3), pp. 509-513. 1991. "Changing Social Security Rules For Workers Over 65: Proposed Policies And Their Effects." Industrial And Labor Relations Review 44(4), pp. 733-745. 1994. "Employer Provided Health Insurance And Retirement Behavior." Industrial And Labor Relations Review.

Kotlikoff, Laurence J. 1995. "Privatizing Social Security: How It Works and Why It Matters". Mimeo. Boston University. September. 
Samwick, Andrew. 1993. "Wage Risk Compensation Through Employer-Provided Pensions." Manuscript. Cambridge, MA.

U.S. Congress, Ways and Means Committee. Various Years. Board of Trustees. The Annual Report of the Federal Old-Age and Survivors Insurance and Disability Trust Fund. 
Figure 1

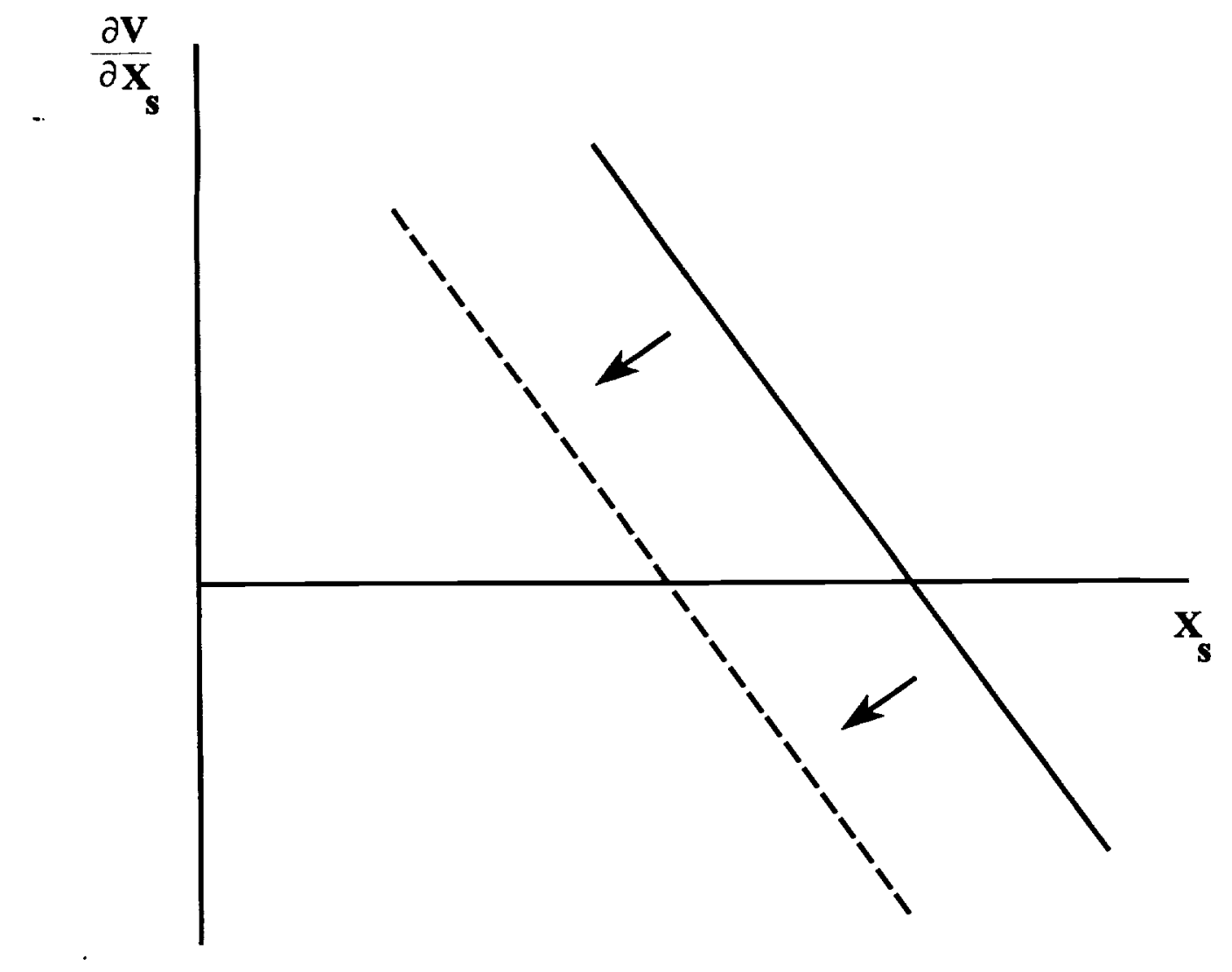


Figure 2

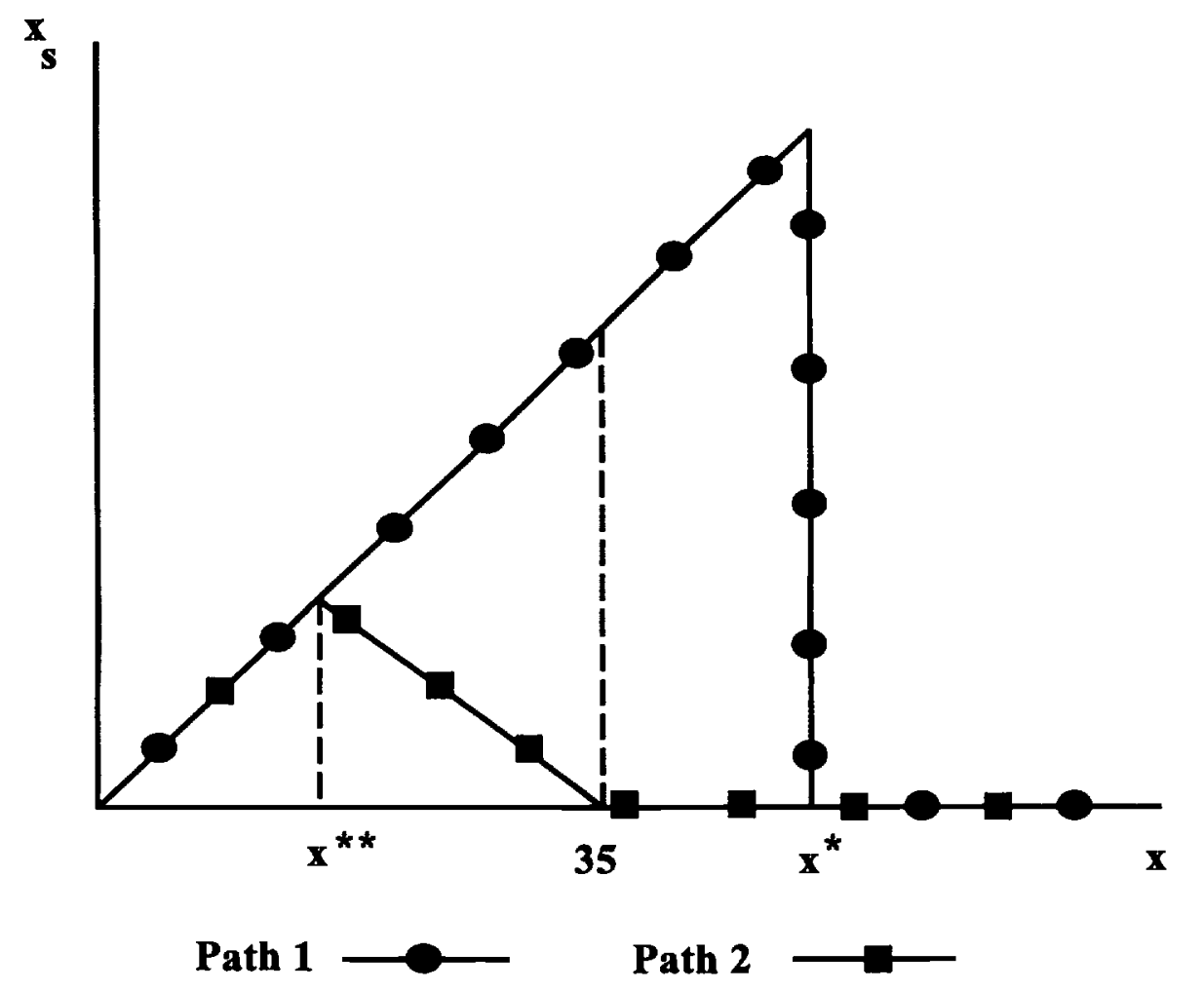


Figure 3

Decline in Social Security Participation with Privatization

Part A

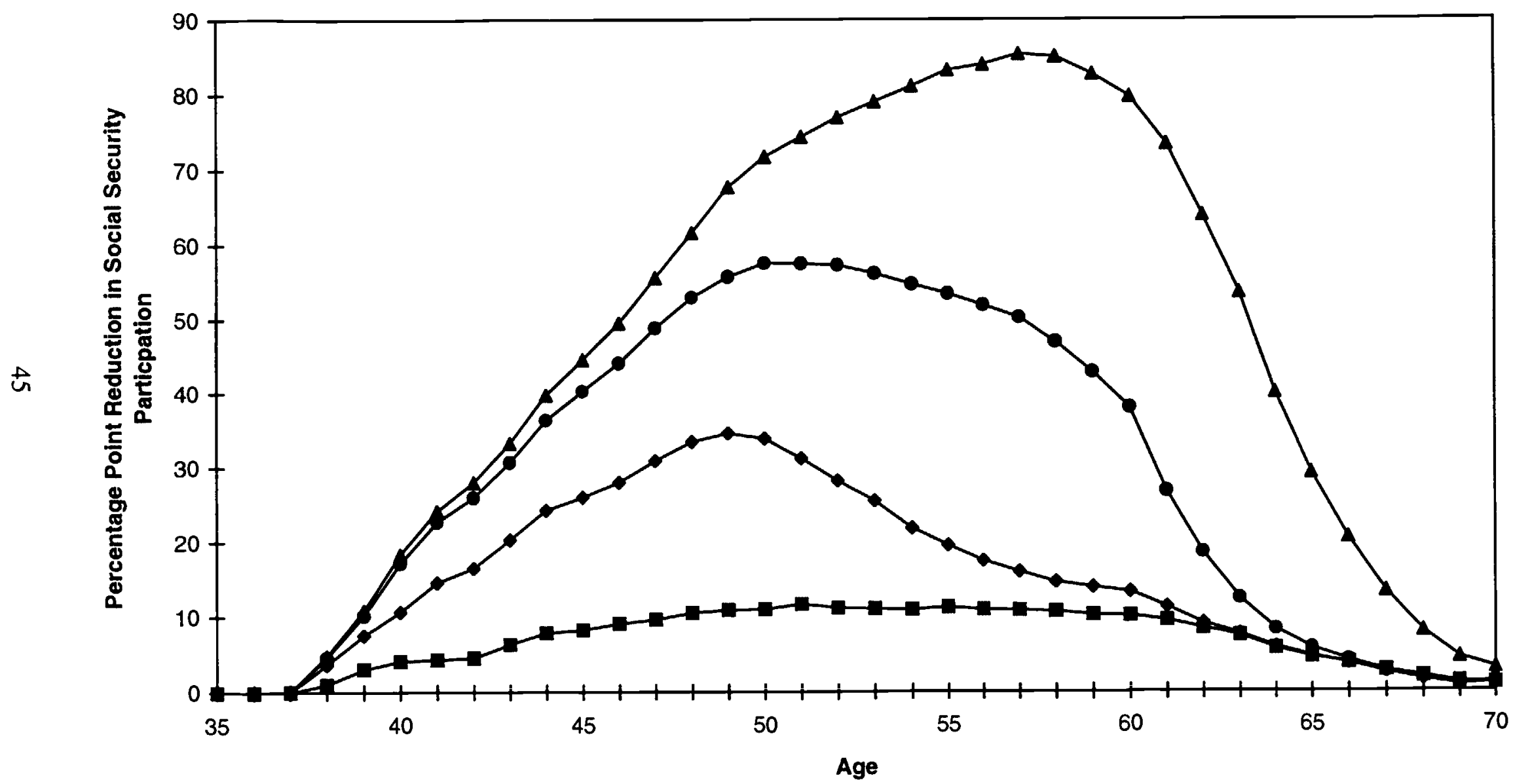

Standard Life Table $\rightarrow-$ Projected Life Table $\rightarrow-$ Value Only Own Benefits $\rightarrow-$ Value Benefits at $80 \%$ 
Figure 3

Decline in Social Security Participation with Privatization

Part B

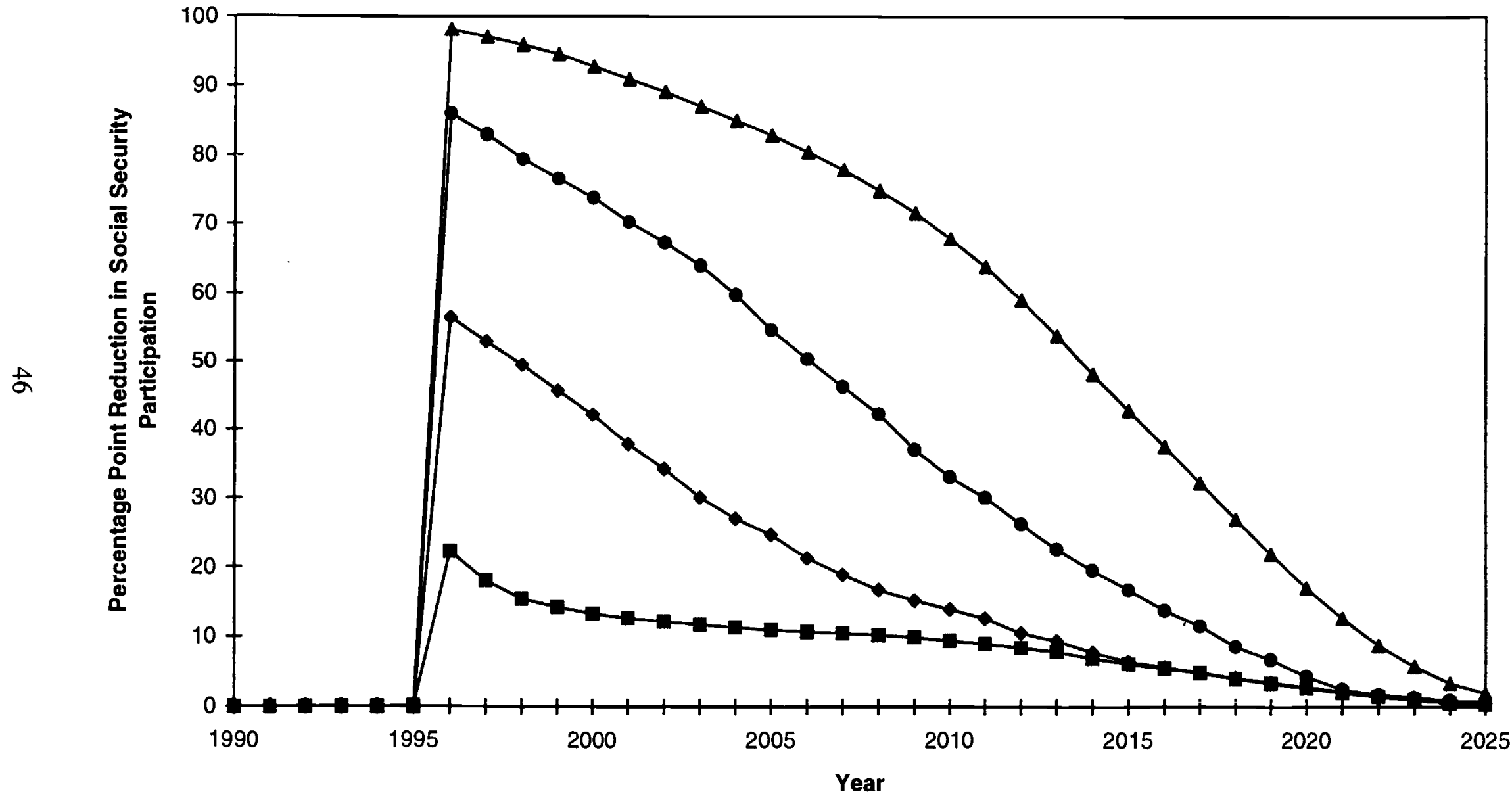

$\rightarrow-$ Standard Life Table $\rightarrow$ - Projected Life Table $\rightarrow-$ Value Only Own Benefits $\rightarrow-$ Value Benefits at $80 \%$ 
Figure 4

Change in Labor Force Participation with Privatization

Part A

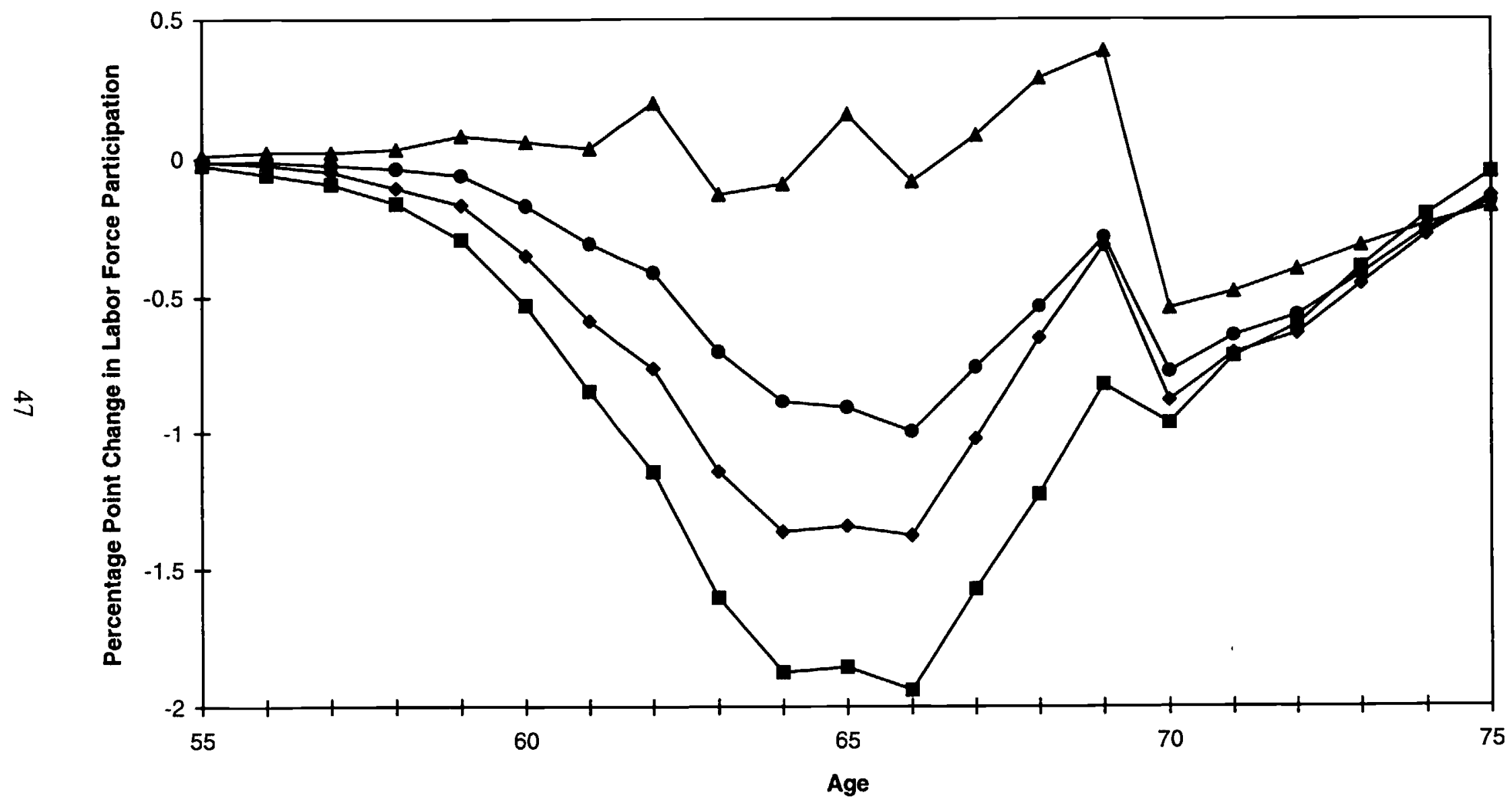

$\multimap-$ Standard Life Table $\rightarrow-$ Projected Life Table $\rightarrow-$ Value Only Own Benefits $\rightarrow-$ Value Benefits at $80 \%$ 
Figure 4

Change in Labor Force Participation with Privatization

Part B

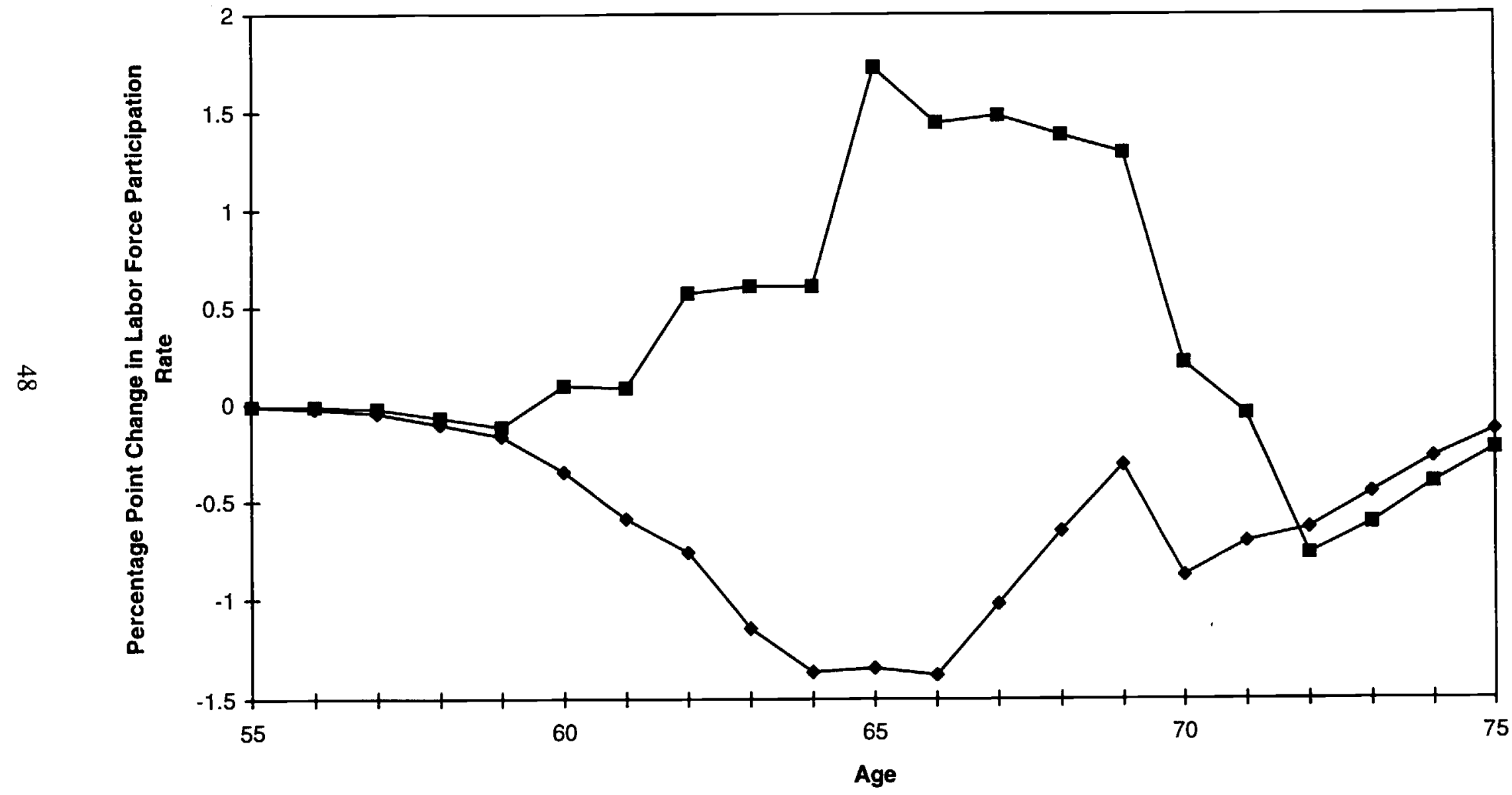

$\rightarrow-$ Pensions Unchanged $\rightarrow-D B$ Pensions Ended 
Figure 5

Change in Payroll Taxes with Privatization :

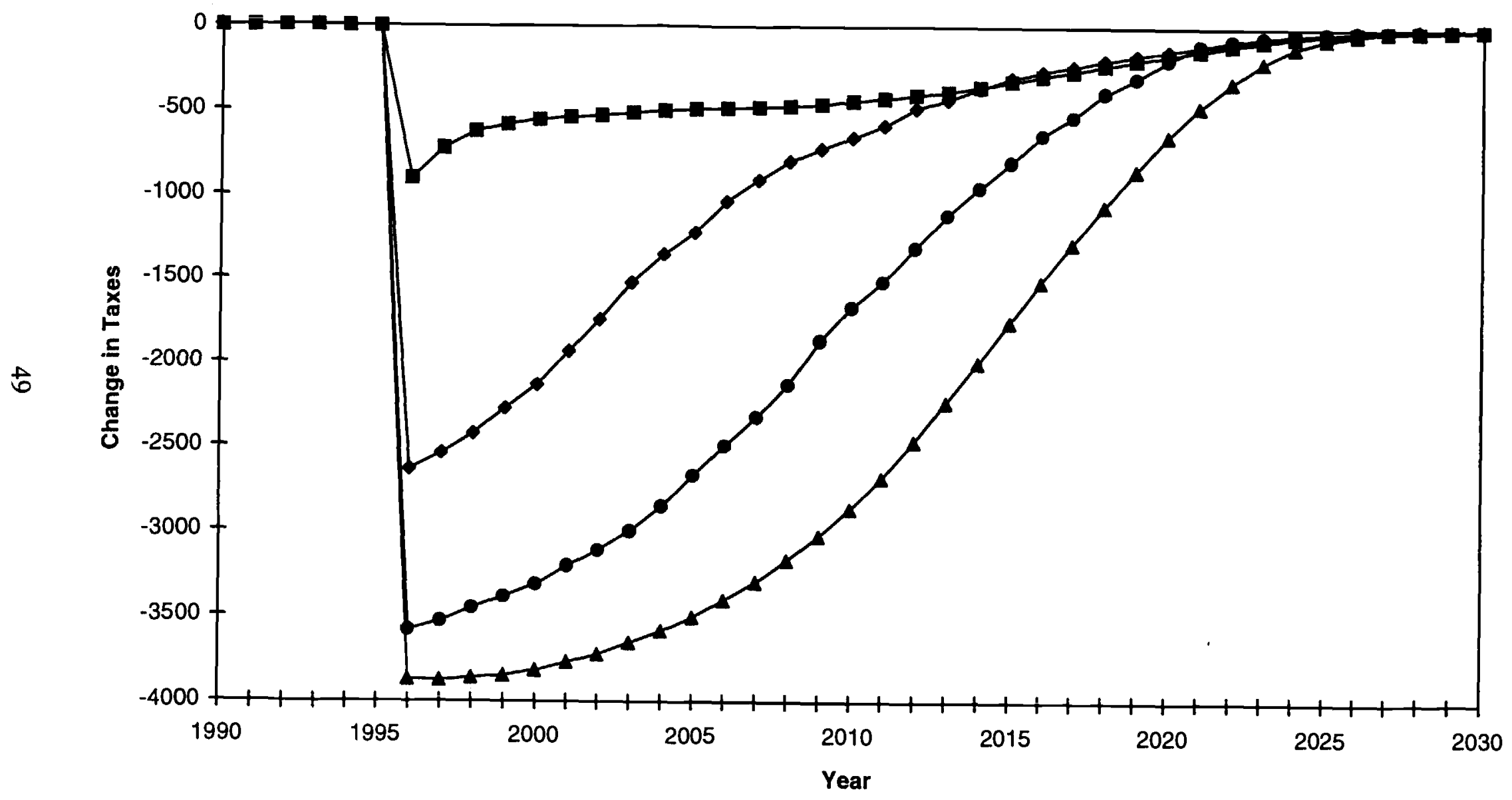

$\rightarrow-$ Standard Life Table $\rightarrow-$ Projected Life Table $\rightarrow-$ Value Only Own Benefits $\rightarrow-$ Value Benefits at $80 \%$ 
Figure 6

Change in Social Security Benefits with Privatization

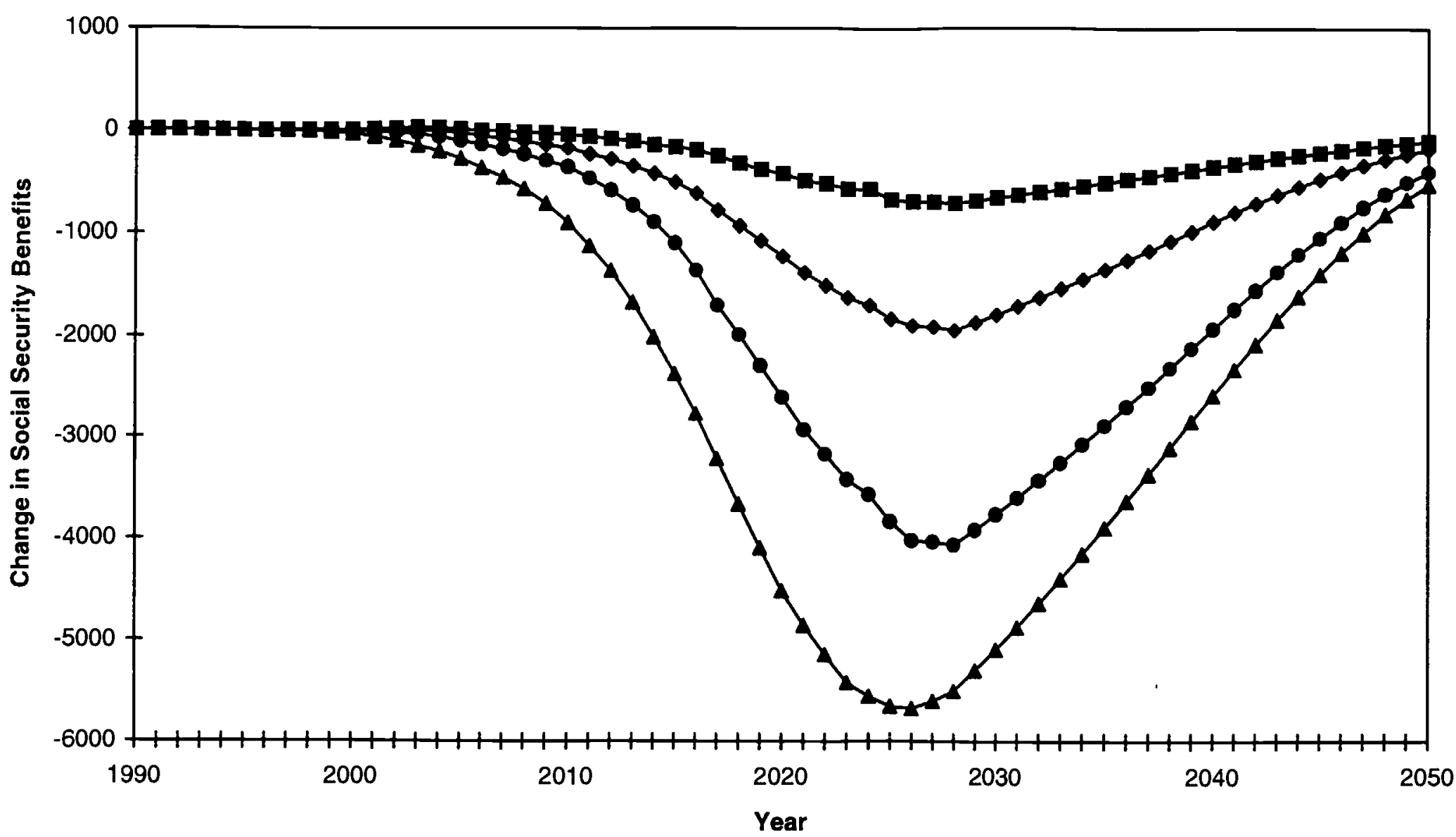

$\rightarrow-$ Standard Life Table $\rightarrow-$ Projected Life Table $\rightarrow-$ Value Only Own Benefits $\rightarrow \bullet$ Value Benefits at $80 \%$ 